\title{
USE OF DATA VISUALISATION IN THE TEACHING OF STATISTICS: A NEW ZEALAND PERSPECTIVE
}

\author{
SHARLEEN FORBES \\ Victoria University of Wellington \\ Sharleen.Forbes@vuw.ac.nz \\ JEANETTE CHAPMAN \\ Otago Girls High School \\ ch@otagogirls.school.nz \\ JOHN HARRAWAY \\ University of Otago \\ jharraway@maths.otago.ac.nz \\ DOUG STIRLING \\ Massey University \\ D.Stirling@massey.ac.nz \\ CHRIS WILD \\ University of Auckland \\ c.wild@auckland.ac.nz
}

\begin{abstract}
For many years, students have been taught to visualise data by drawing graphs. Recently, there has been a growing trend to teach statistics, particularly statistical concepts, using interactive and dynamic visualisation tools. Free down-loadable teaching and simulation software designed specifically for schools, and more general data visualisation tools are increasingly being used in New Zealand classrooms. This paper discusses four examples: the use of GenStat for Teaching and Learning Schools and Undergraduate (GTL); Auckland University's iNZight and VIT (Visual Inference Tools) for teaching bootstrapping and randomisation; the CAST e-books, and the use of data visualisation tools to assist learning concepts in official statistics. All these tools are publically available and several are already being used internationally.
\end{abstract}

Keywords: Statistics education research; Teaching bootstrapping and randomisation; Official statistics concepts

\section{INTRODUCTION AND BACKGROUND}

Advances in Information Technology (IT) have had a global impact massively increasing the ability to store, visualise and analyse very large amounts of information or data. This has caused an explosion in the availability of data visualisation and statistical analysis tools that provide new methods for improving access to and interpretation of data. The web (internet) itself has also become an analysis tool as users often need only access to a computer and an internet browser to be able to explore data, without the need for expensive statistical software. For example, tools like Google Maps (http://maps.google.com/) and Google Earth (http://www.google.com/earth/index.html) have brought spatial data visualisation (geovisualisation) technologies into the public domain and can provide a transition from the

Statistics Education Research Journal, 13(2), 187-201, http://iase-web.org/Publications.php? $p=$ SERJ C International Association for Statistical Education (IASE/ISI), November, 2014 
traditional static graphs to dynamic and interactive graphics that can be used in the formulation of hypotheses. Sophisticated analytical capability is now in the hands of the general public without the need for expensive licenses. Recent data visualisation tools have three major advantages: they are free, easy to access (either on-line or as open-source software) and present complex information in an easy to interpret visual format. The caveat is that users need to know how to use it. But the gap between statistical practice and statistics education is increasingly widening. Moore (cited in Rossman, Dietz, \& Moore, 2013) stated that no amount of formal mathematics can replace the pictorial vision students need to grasp the concepts of statistical inference. Technology has made many forms of visualisation available to teachers and students, and raised expectations that it would bring with it changes in statistics education. However, Cobb (2007) thought that statistics education remained trapped by what was computable in the twentieth century. To what extent is this still true? How are teachers taking advantage of visualisation tools in the statistics classroom? Is it changing what and how they teach?

This paper introduces four visualisation tools, and compares and contrasts how each is used. Each is publicly available on the internet at no cost to the user, and each is also currently being used in New Zealand classrooms. Some have already been used in other countries and all have the potential to be used internationally.

\subsection{GROWTH OF TECHNOLOGY}

Moore (cited in Rossman et al., 2013) suggests that "the late 1980s were still the dark age for graphics" (p. 9). The earliest use of computers to help teach statistical concepts involved simulations to demonstrate the consequences of randomness. In particular, simulations could build empirical distributions for summary statistics and use them to illustrate the Central Limit Theorem, could demonstrate that about $95 \%$ of $95 \%$ confidence intervals include the actual parameter value, and could illustrate the fact that $\mathrm{p}$-values are uniformly distributed between 0 and 1 when the null hypothesis holds. Initial implementations however involved the writing of programs whose code explained the mechanism of the simulation, but whose output simply showed results (e.g. Engel, 1986). It was only after the appearance of personal computers with graphical user interfaces in the 1980s that programs such as StatLab (Stirling, 1990) could animate the repeated sampling and accumulation of sampling distributions underlying the simulations, making them more effective teaching tools. Interaction could also be incorporated, both through clicking a button to generate each simulated sample and by allowing users to investigate 'unusual' simulated results to see the samples from which they were generated.

Generalising from specific simulations built into early simulation programs, Fathom (Finzer, 2001) provides a framework for defining and animating a wide range of different simulations. It has been widely used for teaching concepts, especially at high school level. Simulations can effectively explain how randomness dictates the properties of summary statistics, confidence intervals and hypothesis tests, but dynamic diagrams can also help to explain other specific statistical methods without simulation. Robinson and Bowman (1990) gave some early examples such as animation of splitting values into stems and leaves to build dynamically a stem and leaf plot.

Computer demonstrations of concepts were initially implemented as programs that had no built-in instructions for usage. Although fine for instructors, most students needed separate instructions to guide them through usage and to explain the concepts that were being illustrated. The wide availability of web browsers and the Java programming language in the late 1990s allowed dynamic and interactive visualisation of concepts to be incorporated seamlessly into wider instructional material.

Two of the specific discussed in this paper were developed specifically for the New Zealand senior secondary school, Auckland University's iNZight software and GenStat for Teaching and Learning Schools and Undergraduate (GTL) in schools, although both are also applicable to first-year university courses. The third initiative discussed is a teaching e-book that makes extensive use of simulations (CAST, Stirling, 2013) and has been used in Kenyan university courses (Stern, 2012) as well as in New Zealand. The fourth example is not a single 
piece of software but discusses the use of publicly available data visualisations to teach official statistics concepts (Forbes, 2012).

\subsection{STATISTICAL CONCEPTS}

Alongside the rapid changes in technology there has also been a change of focus in statistics education to a 'mode of thinking rather than a technical discipline' (Rossman et al., 2013, p. 14). Cobb (2007) that technology provides us with a way to become free of 'the tyranny of the computable' (p1) and that we can now focus on developing underlying statistical concepts such as chance and variation.

In most final secondary school year and introductory university statistics courses the conceptual foundations underpinning inference are the normal distribution, the Central Limit Theorem and the sampling distribution of estimators. Research evidence, however, suggests that these theoretical and mathematical procedures act as a barrier to students' understanding, and the statistical inference concepts are inaccessible to the majority of students (e.g., Sotos, Vanhoof, Noortgate, \& Onghena, 2007). Computer-based methods can be used to make the abstract concrete by providing "visual alternatives to classical procedures based on a cookbook of formulas" (Hesterberg, 2006, p. 39). These visual alternatives have the potential to make underpinning concepts and processes transparent, more accessible, and connected to physical actions. Students experience a set of general approaches or a method that applies across a wide variety of situations to tackle problems rather than learning multiple and separate formulas for each situation (Wood, 2005). Moreover, these methods, coupled with dynamic visualisation infrastructure, allow access to statistical concepts previously considered too advanced for students, as mastery of algebraic representations is not a prerequisite. For example, as Wood (2005, p. 9) states, simulation approaches such as the bootstrap "offer the promise of liberating statistics from the shackles of the symbolic arguments that many people find so difficult". The use of new computer-based statistical inference methods using re-sampling approaches is pervading practice (see Hesterberg, 2006, for a concise description) and there are strong pedagogical arguments for introducing the bootstrap and randomisation methods into the curriculum.

A new mathematics and statistics curriculum was implemented in New Zealand schools in 2008. The statistics curriculum is characterised by its data handling, and in more recent years, data visualisation approach. In 2013 bootstrapping and randomisation were added to the curriculum achievement objectives for the senior secondary school (Ministry of Education, 2012). National Certificate of Educational Achievement (NCEA) standards were realigned progressively with the curriculum between 2011 and 2013 as students moved through schools. These standards can be taught and assessed effectively only with the help of statistical software for analysing and graphing data.

There is a lack of research that determines whether using visualisation tools in the classroom leads to greater conceptual understanding of students, than using traditional mathematics based methods. This paper does not attempt to do this but categorises the design and use of the four visualisations against the following simple framework given in Table 1. Here the column heading 'Design' means specifically designed for learners and the heading 'Classroom use' means that it is currently being used in classrooms. A table (Table 2) comparing the four visualisations is given in the conclusions.

Table 1. Categorisation of visualisation design and use

Design Classroom use

Visualise statistical data

Enhance conceptual thinking

Investigate real world data

Design research that aims to develop theories about learning and instructional design as well as to improve learning and provide practitioners with accessible results and learning 
materials (Bakker, 2004) was used with the iNZight and VIT tools as part of a formal statistics education research project investigating appropriate pedagogy for teaching inferential concepts using randomisation and re-sampling techniques. A student survey was used to evaluate the effectiveness of the GTL software in the classroom but the educational benefit of the other tools was largely derived from formal student and informal teacher feedback.

\section{INZIGHT AND VIT}

iNZight and VIT are free, open-source software systems whose development has been led by Chris Wild at the University of Auckland. While both are specifically designed for learners, they have logically very different roles and functions; iNZight is for analysing data whereas VIT is primarily for conceptual development for statistical inference (although the VIT modules do have some limited data-analysis capabilities). They are packaged together as iNZightVIT. Their download pages had over 56,000 hits in 2013.

\subsection{INZIGHT}

iNZight (https://www.stat.auckland.ac.nz/ wild/iNZight/) is data-analysis software with the aim of "facilitating getting further into the world of data faster". It facilitates the rapid exploration of multivariate data using simple forms of graphics without the distractions of driving complex software and minimising the need for the user to remember "the names of things". It prioritises looking at the data. Thus, graphics always appear instantly whereas summaries and formal inferential information have to be summoned (with a button click). It attacks the getting-further-faster problem by minimising system complexity and using intuitive metaphors. System complexity is kept low by confining choices to the very biggest decisions with everything else happening by default. The system is written in $\mathrm{R}$ but users on Windows and most Mac operating systems need not know anything about that. It is currently extensively used in New Zealand schools, particularly in the last year of high school, but has growing capabilities for undergraduate and some graduate level applied statistics. Unfortunately R does not run on tablets and smart phones, which is a crucial deficiency in an increasingly 'bring your own device' educational world. Consequently work on an online version of iNZight using webpages interacting with software running on a remote server began at the end of 2013. The online version is now almost complete. Its home URL has not yet been determined but it will be linked off the main iNZight homepage when it becomes available.

\subsection{VIT}

VIT (https://www.stat.auckland.ac.nz/ wild/VIT/) provides teachers and students with an integrated suite of dynamic visualisations of aspects of statistical inference covering: sampling variation, bootstrap confidence intervals, confidence interval coverage, randomisation variation and randomisation tests applied to data features: proportions, means, medians, quartiles, interquartile ranges, group differences in these features (including analysis of variance) and regression slopes. This is user-driven software using user-input data (population or sample as applicable). The visualisations are designed for "connecting all the conceptual dots" in the processes involved and maximising conceptual transfer. The software is designed to facilitate both teacher demonstration and student activities. Currently the VIT modules of iNZightVIT are most widely used in the last year of high school in New Zealand. Development of VIT has been running just in front of pedagogical research involving its use with improvements made triggered by lessons learned in the research. A major paper on the pedagogy drivers for VIT and its use in teaching is being revised for the International Statistical Review. However, for some early results of the educational research, see: Budgett, Pfannkuch, Regan, and Wild (2013), Parsonage, Pfannkuch, Wild, and Aloisio (2012), Pfannkuch et al. (2011), Pfannkuch and Wild (2012, 2013), Pfannkuch, Wild, and Parsonage (2012), Pfannkuch, Wild, and Regan (2014), and Pfannkuch, Forbes, Harraway, Budgett, and Wild (2013). 


\section{GTL (GENSTAT FOR TEACHING AND LEARNING) SCHOOLS AND GTL UNDERGRADUATE}

Statistical software to use when analysing and graphing data can be expensive. Opportunities to access software which covered the New Zealand school curriculum were explored in 2010. One proposal came from Vision International (VSNi) after overtures about the provision of software for use in schools. They proposed the development of a free shortened menu version of their package, GenStat (www.vsni.co.uk/software/genstat-teaching/), with the facility to upload data from Excel or other sources and allow for sample sizes up to 2500 and 80 variables. All graphical procedures from their full package would be included. This software would be available for home computers, convenient given a trend towards students bringing their own computers to use at school. It was recognized that availability of free software to investigate large data sets could enhance an appreciation of statistics in the classroom and aid learning in the subject.

Instructional lessons covering the New Zealand school statistics curriculum can be accessed on the website www.maths.otago.ac.nz/videos/statistics/GenStatLessons (Figure 1). The lessons cover classes in the early years of high school (ages 13 to 16) and more advanced topics in the final two years of school (ages 16 to 18). A good start is the introductory lesson, Getting Started with GenStat, a six-page manual providing basic skills for navigating around GenStat, for opening files and for performing basic analyses. Further lessons cover bivariate data, time series and bootstrapping as well as the use of statistics in biology.

The website www.maths.otago.ac.nz/videos/statistics hosts 19 videos (Figure 2) featuring 19 researchers, discussing the context of a current study and presenting relevant data in an Excel file which can be loaded into GTL or any other software for analysis. GTL lessons are included for 13 of the videos. Several videos from an earlier GTL workshop for teachers can also be accessed. In 12 months, over 19000 unique external hits on this website have been recorded.

\subsection{LICENSE APPLICATION PROCEDURE AND INSTALLATION OF GTL}

GTL Schools and GTL Undergraduate can be installed in a school or university or on a home computer once the local IT coordinator has received the license. The process in place for obtaining a download and license is as follows:

(i) The teacher asks their IT coordinator to contact $\mathrm{VSNi}$ at the website www.vsni.co.uk/software/genstat-teaching/ and apply for a download by email info@vsni.co.uk or phone +44(0)1442 450230.

(ii) Once VSNi receives a signed End User Licence Agreement, a token is emailed to the IT coordinator along with the download and a time-limited license key based on an academic year. Individual students at the site can now be licensed freely via the network license. Schools update the license easily for subsequent years.

If an institution installs the software onto a networked drive, networked PCs only need point to the .exe file on the server to work, with no need to run the installation on each PC on the network. Although this does not give integration of the GenStat files into Windows Explorer, which requires a local installation on each PC, all files can be opened from within GenStat as normal. 


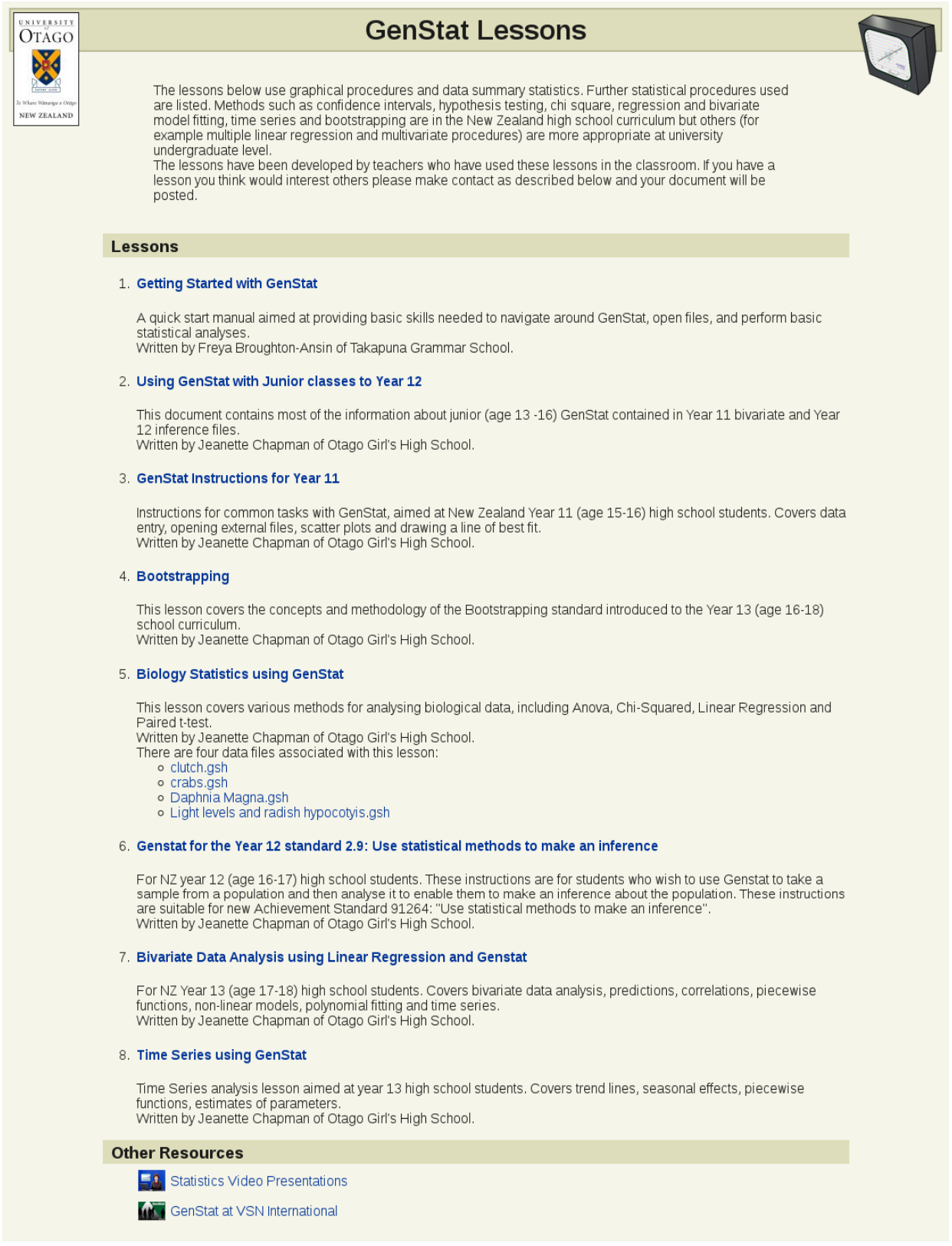

Figure 1. Screenshot of GenStat school lessons. 


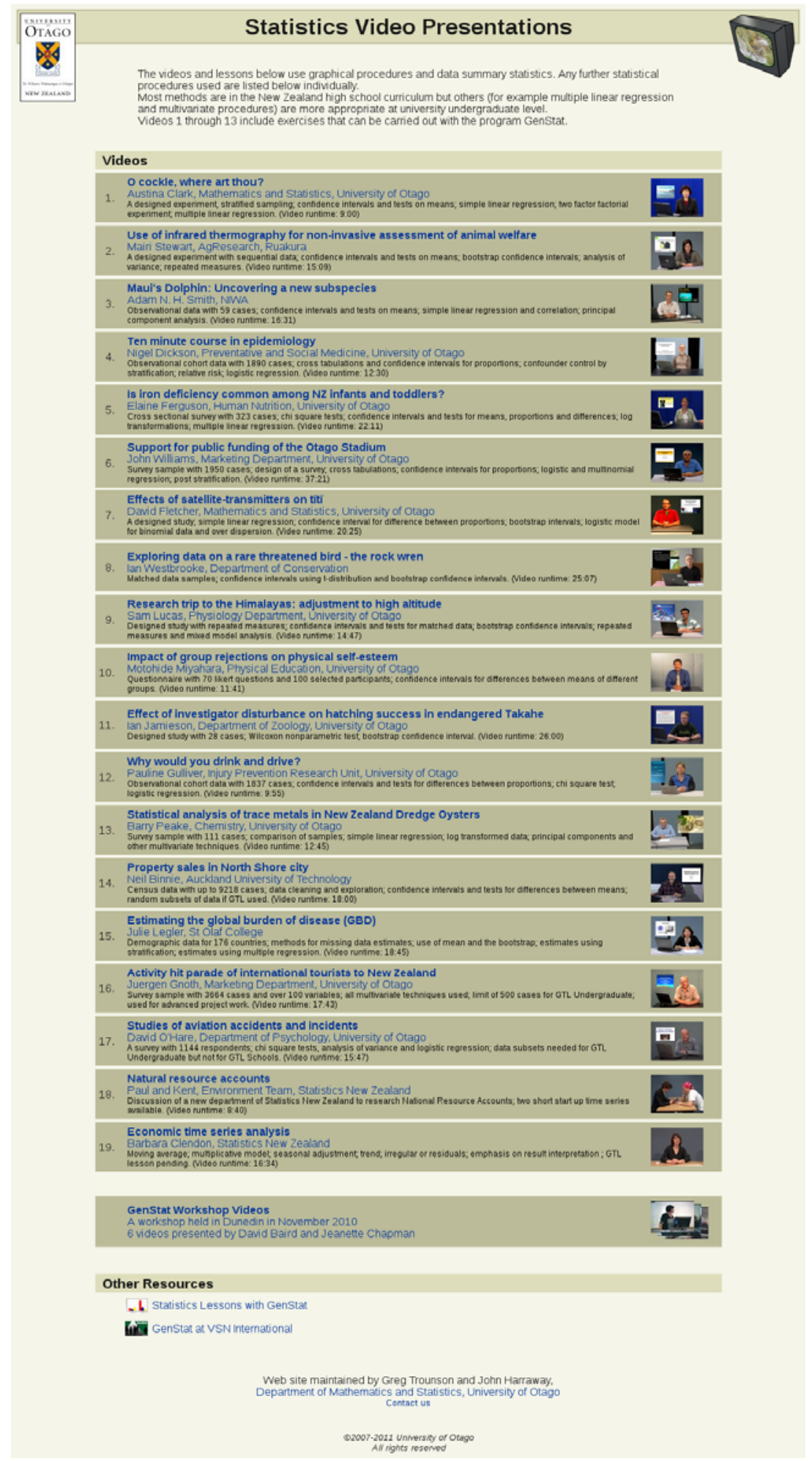

Figure 2. Screenshot of 19 statistics case study video presentations. 


\subsection{TEACHER COMMENT AND STUDENT REACTION TO GTL SCHOOLS}

Teachers' opinions on their use of GTL in junior and senior high school with all levels of ability have been reported (Harraway, 2012). Five teachers interviewed reported that they found GTL helpful and easy to use. Also reported were the results of a survey of 41 students who enjoyed the experience of using the software with 36 of the 41 stating that they would NOT prefer to use different software and 20 finding it fairly easy or easy to use. Discussion at the New Zealand Mathematics Teachers Conference, Wellington October 2013, identified further benefits associated with use of GTL:

(i) Data can be manipulated easily to construct groups or split data files allowing analysis of a range of problems in different ways and allowing methods to be explored and compared. Students can restrict on groups or values of variables.

(ii) In the junior school students need to establish an appropriate graph for summarising data. Lower ability students in junior classes have no problem mastering this skill.

(iii) Students focus on interpretation of results as the tedium of calculation is removed. A built-in calculator makes it easy to perform calculations.

(iv) Summary graphs and descriptive statistics become exciting and interesting.

(v) The case study data sets available in GTL are excellent for classroom use and lesson planning.

(vi) Data from many sources and in many formats can be accepted in GTL including the New Zealand CensusAtSchool (www.censusatschool.org.nz) and associated resources. It is also possible to export to other programs.

(vii) Control icons in GTL are similar to those in Word which makes result reporting easy.

(viii) Dialogue boxes use words like "explanatory" and "response" which result in useful discussion about what is to be predicted. This also leads to discussion of a model.

(ix) Residuals and fitted values after fitting a model can be saved in a spreadsheet for future exploration. This is also the case with the bootstrap lesson which is reported on the website.

All mathematics teachers at a large girls' high school have chosen to use GTL for all students aged 13 to 16 in the school. In their final year 90 students aged 17-18 in four classes use all the options available in GTL. Biology students have also used GTL for projects at the school. Another survey of 19 final school year biology students aged 17-18 years found that 9 used GTL and 10 used EXCEL. Those who used EXCEL did so for several reasons, including that it 'was available at home'. However, 2 of these 10 would have used GTL if they had known how. One of the students using GTL reported that 'it was easier for the line graphs'.

GTL has a potential to build understanding of statistics in ways which will appeal to school students and motivate learning in statistics. It is always exciting investigating large data sets where results are unclear. GTL provides a platform for students who bring their own laptops to school. The lessons on the website have been developed by practicing teachers. The lessons can be used as resources for teaching the new achievement standards in New Zealand.

\section{CAST}

CAST is a resource that is more focused on teaching traditional statistical concepts than are Genstat or iNZight/VIT. Its development was motivated by the potential of interactive computer graphics to illustrate and demonstrate the properties of summary statistics, confidence intervals and hypothesis tests through simulations, but it was also found that interactive diagrams could help to motivate and explain many other statistical ideas.

The initial release of CAST (Stirling, 2002) was effectively a web-based introductory statistics textbook (e-book) that interspersed text and static diagrams with over 300 interactive and dynamic diagrams; these were implemented as Java applets and illustrated key statistical concepts. Recent releases added further applets and additional e-books about multiple regression and experimental design.

Figure 3 shows two examples from CAST in which simulations demonstrate concepts relating to inference; in each case, static text surrounding the diagram gives instructions for 
using it and explains what is being demonstrated in words. The diagram on the left uses simulated data from a normal linear model to demonstrate that $95 \%$ confidence intervals for a regression slope have probability 0.95 of including the underlying parameter (http://cast.massey.ac.nz?book=general\&page=regnEst6); intervals not including the model's slope are shown in red and can be clicked to display the data underlying them. The diagram on the right explains that the p-value for testing whether a linear model's slope is zero is uniformly distributed between 0 and 1 when the null hypothesis of zero slope is true; changing the model slope at the top allows simulation of the distribution of p-values when the null hypothesis is false (http://cast.massey.ac.nz?book=general\&page=regnTest4).

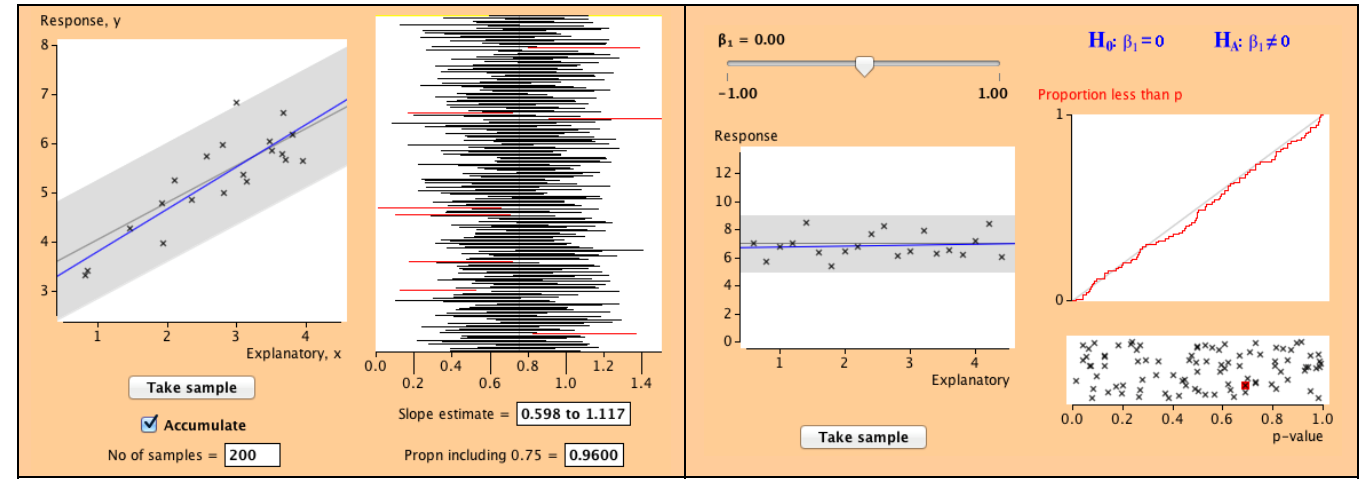

Figure 3. Properties of $95 \%$ confidence intervals and p-values.

Figure 4 shows four diagrams in which dynamic diagrams illustrate other statistical concepts. The top-left diagram illustrates the effect of class width on the smoothness of histograms (http://cast.massey.ac.nz?book=general\&page=density3). The top-right diagram shows how the proportion of explained variation affects the sums of squares and $p$-value in an anova table (http://cast.massey.ac.nz?book=general\&page=multiGroup7). The bottom-left diagram demonstrates the meaning of a normal linear model (http://cast.massey.ac.nz?book=general\&page=regnModel2), and the bottom-right diagram shows how least squares minimises the sum of squared residuals, the total blue area (http://cast.massey.ac.nz?book=general\&page=leastSqrs4). In all of these examples, visualisation explains the concepts more clearly than words and interaction with the diagrams help students to understand the mechanism behind them.

Java applets are still the only widely-available technology for including complex interactive graphical diagrams in web pages, but recent security issues with Java have resulted in browsers and operating systems disabling Java by default. Although students can still enable it on laptop and desktop computers, Java applets cannot be used on tablet computers and smartphones. An alternative is to present the diagrams as videos. Although inability to interact with the diagrams in a video removes the active learning component, a voice-over can explain what the diagram shows more fully than is feasible in words on a web page. The most recent release of CAST (Stirling, 2013) contains alternative video versions of the interactive diagrams in one introductory e-book. CAST is freely available under a Creative Commons licence.

Internal students have generally been positive about how the interactive diagrams in CAST help to explain statistical concepts. Distance students, however, are often older and are less comfortable with studying on a computer, so we also provide references to a second paperbased textbook to cope with different styles of study. As computers in their varied forms become more ubiquitous, we anticipate that e-books will become more widely accepted. 


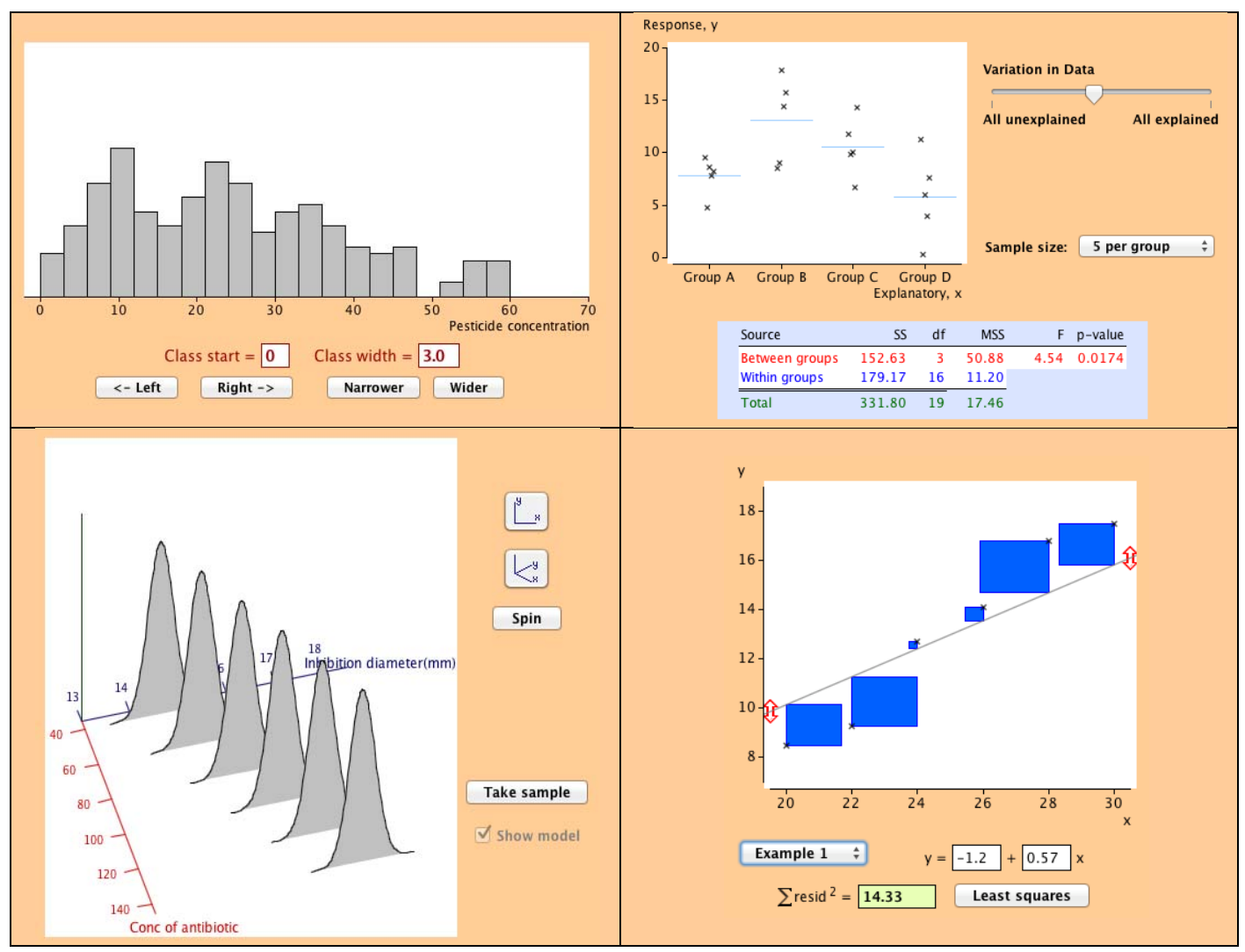

Figure 4. Dynamic visualisations of other statistical concepts.

One particularly useful feature in CAST is the ease with which customised e-books can be created to match the needs of particular courses or groups of users. Customised e-books are being used as the main textbooks in three introductory statistics courses at Massey University. Another has been written to support the New Zealand high school curriculum and several are being used by different groups in various parts of Africa. Stern, (2012), reported that there was a clear difference in final exam marks between Kenyan students taught using CAST and those that were not. The use of CAST in Kenyan was part of curriculum development 'moving away from statistical theory and specific techniques, to an understanding of principles and the ability to apply them' (p. 3) but Stern, Coe, Stern, and McDermott (2012) report that it was mainly used as an electronic textbook for background reading.

\section{USE OF PUBLIC DATA VISUALISATIONS TO TEACH CONCEPTS OF OFFICIAL STATISTICS}

There are also an increasing number and variety of data visualisations available in the public domain. The primary purpose of most of these is the dissemination of information but as Forbes (2012) reported they can also be used in classrooms to both motivate students with limited mathematical backgrounds and to reinforce statistical concepts. While the basic statistical concepts of chance and variation that underlie statistical inference are also important in official statistics there are also other concepts that are equally important. For example, important concepts in the macroeconomics area are those of index numbers and weighting, and in the demographic area concepts of population growth, decline and momentum are important.

No discussion of these visualisations would be complete without reference to the work of Hans Rosling (2007). His Gapminder 'bubble' graphs were used in class to interrogate international data and step students from the simple bivariate situation to multivariate models. Three-dimensional scatterplots created using the open- source software package ' $R$ ' (www.r- 
project/org) were used to enable students to see and discuss the multivariate concept of interaction. Several other visualisations were also used to demonstrate the power of quantitative information for informed decision making, including:

a mapping tool (Commuterview) displaying commuter data at local authority levels in New Zealand. Figure 5 demonstrates the complexity of public transport needs in New Zealand's most densely populated city, Auckland.

- use of GeoVista (open-source geovisualisation software, available from the GeoVISTA Center, 2012) to investigate the geography and statistical relationship between 2006 Census variables in the Auckland region and some of the policy applications the tools have been applied to (such as the relationships between fear and occurrence of crime, between dwelling density and occupancy rates and the geographic distribution of overcrowding in households). Student feedback indicated that they enjoyed working with these tools. It included the statement that "visual tools helped to further my understanding of different methods for presenting complex data...I have found in my work that how the information is presented to decision makers is sometimes as important as how the data was collected or analysed."

- Dynamic population pyramids (derived from official Census and official population projections, www.stats.govt.nz/tools_and_services/interactive-pop-pyramid.aspx) showing the demographic transition from growth to decline and vice versa (population growth resulting from a youthful age structure or population decline resulting from an older age structure - the demographic momentum concept).

- A Price Kaleidoscope (Figure 6) demonstrating the concept of weighting in the Consumers Price Index (CPI) that is used in New Zealand to adjust social welfare benefit rates, in wage negotiations and by the Reserve Bank to set mortgage interest rates therefore impacting on almost all residents in some way.

The CPI measures the quarterly price change of representative goods and services (the basket of goods) but Forbes (2012) reported that students with limited mathematical backgrounds find the formula difficult to interpret but quickly develop an understanding of the impact of the weight (expenditure) of a particular group of goods on the overall CPI value when presented with a visualisation such as the Price Kaleidoscope. In this visualisation as shown in Figure 6, the CPI is represented by a circle with each group (and subgroup) having an area proportional to its weight. Clicking on an area in the circle displays its weight and quarterly change in price. Students explore the impact of the weights by moving back-and-forth between the group and its weight as represented by its area, and the overall CPI. The CPI is an important macroeconomic indicator throughout the world. It is also frequently reported by the media (e.g., www.3news.co.nz/Consumer-Green-Party-want-official-dairy-inquiry/tabid/367/articleID/204065/Default.aspx)

and is also now regularly published by the New York Times (see Figure 14) http://www.nytimes.com/interactive/2008/05/03/business/20080403_SPENDING_GRAPHIC.html? r $\mathrm{r}=0$ ) raising the question of whether more of our statistics teaching should be focussed on the interpretation of these new graphical forms. Weights are also used in many composite indices used by international agencies such as the UN and OCED and these are increasingly being presented as visualisations (e.g., Hidaglo's (2010) tree representation of the UN Human Development Index (HDI) and the OECD's Better Life Index (OECD, 2011). 

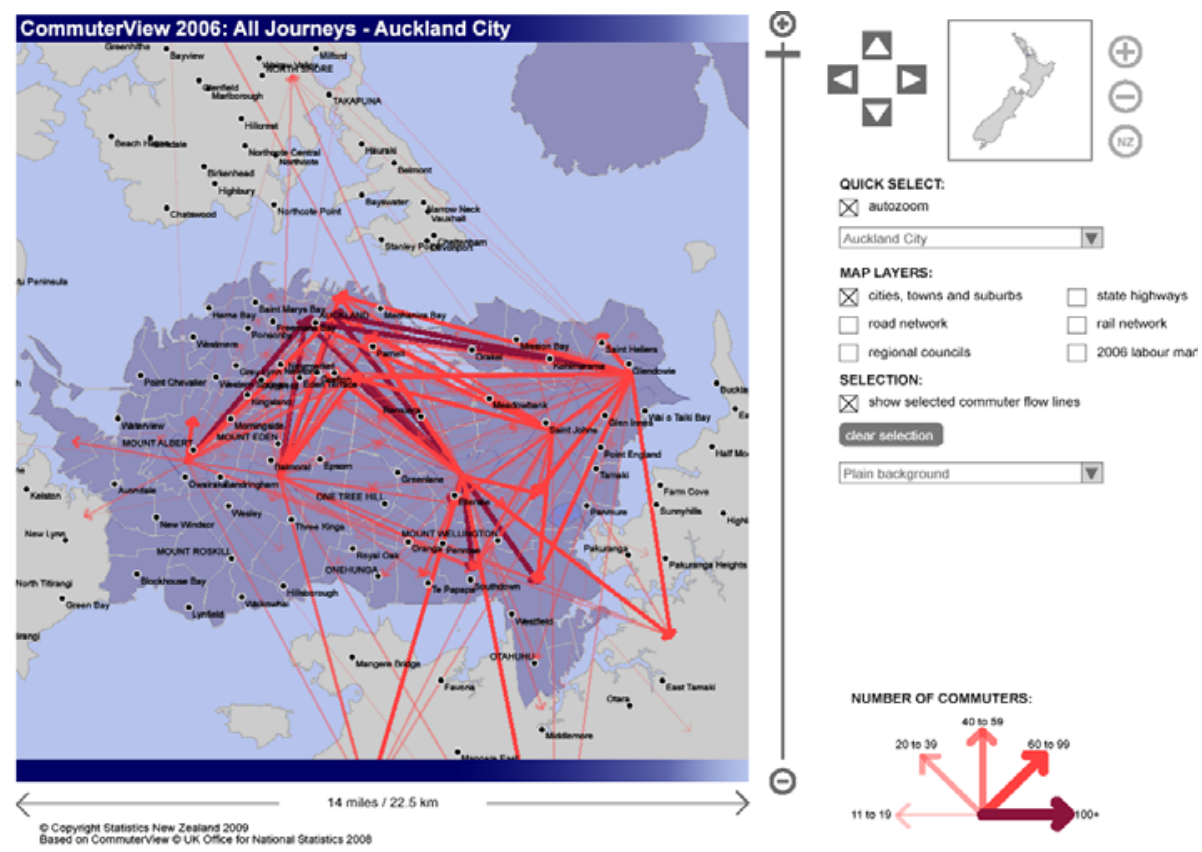

Figure 5. Spider graphs of commuting patterns (from home to work) in Auckland city.

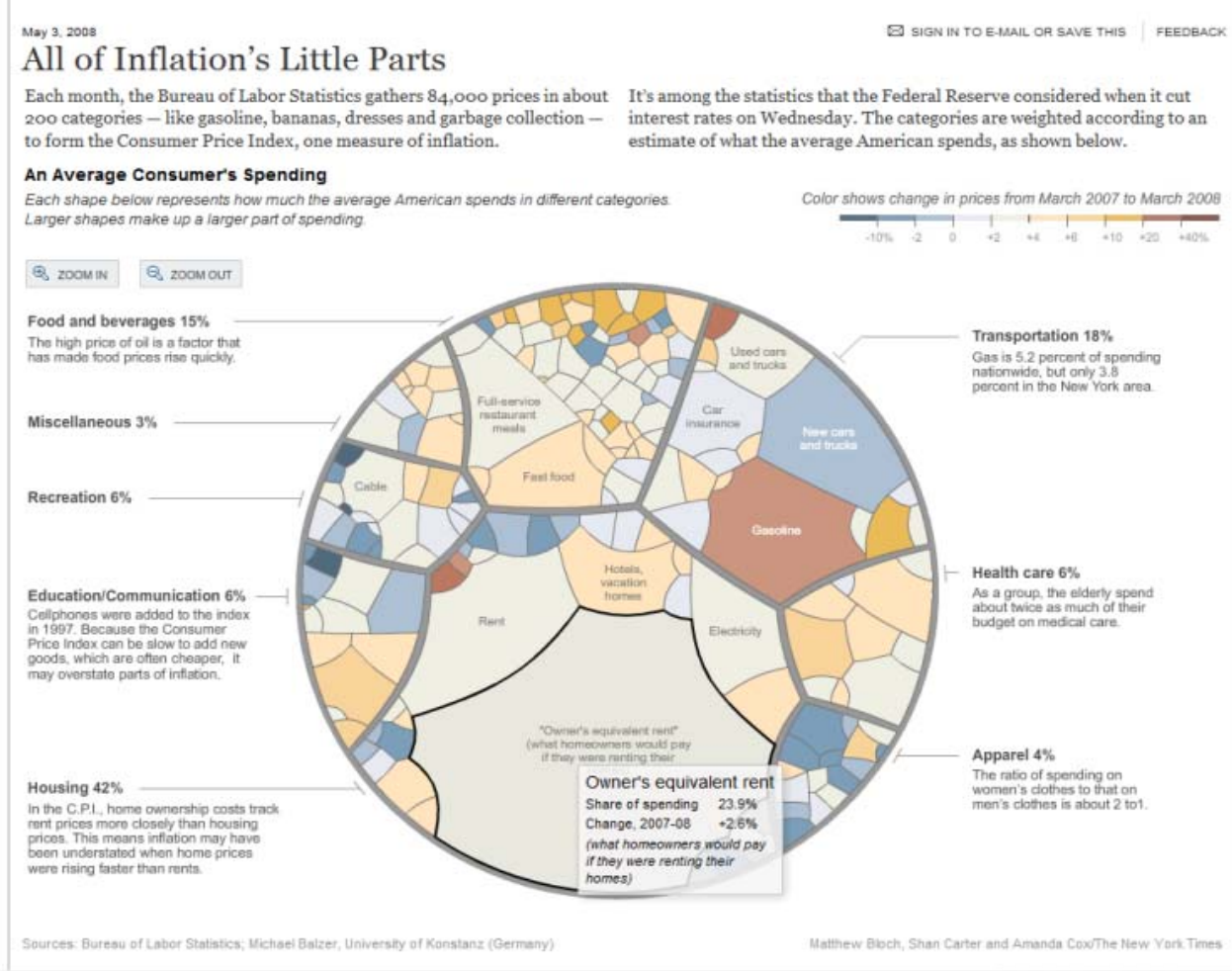

Figure 6. Price Kaleidoscope (New York Times, accessed 15 August, 2013).

From a teaching perspective, these tools were powerful motivating devices. Student feedback indicated that they enjoyed working with the tools and included the statement that "visual tools helped to further my understanding of different methods for presenting complex 
data.... have found in my work that how the information is presented to decision makers is sometimes as important as how the data was collected or analysed."

Although not designed to teach conceptual understanding, the Price Kaleidoscope was an effective way of describing the weighting concept with students quickly being able to interpret the contribution of group changes to the overall CPI, something that can be difficult to achieve with traditional mathematics based methods. Similarly, the Dynamic Population Pyramids tool helped students explore the demographic momentum concept. All the tools provided students with fun, practical, real and appropriate cross-curricular data handling opportunities to investigate patterns using real data from their own real world.

One caveat of the use of public data visualisations is that, although these can be useful teaching tools for demonstrating the patterns and relationships between variables as shown above, the visualisations can also mask both variation and the quality of the underlying data, so they need to be used with discretion and care.

\section{CONCLUDING COMMENTS}

There is evidence from statisticians that pictorial representations are better retained than numerical summaries (e.g. Tufte, 2001) but there is little international research evaluating which groups of users interpret or use these new representations correctly. For example, de Róiste, Gahagen, Morrison, Ralphs, and Bucknall (2009) reviewed literature within management science, decision science and systems examining the benefits of graphs over tables and vice versa and found the results to be conflicting. Further statistics education research in this area is needed. The type of research conducted in the development of the iNZight software needs to be repeated with other tools and possibly used to compare the effectiveness of different tools.

The student and teacher evaluations reported here indicate that all the software discussed in this paper has merit. It may well be that each is useful for different purposes and different sets of learners. This may also be an area for future research. Table 2 provides a summary of the four visualisations,

\section{Table 2. Classification of visualisation tools}

\begin{tabular}{lcccccc}
\hline Tool & \multicolumn{2}{c}{$\begin{array}{c}\text { Visualise statistical } \\
\text { data }\end{array}$} & $\begin{array}{c}\text { Enhance conceptual } \\
\text { thinking }\end{array}$ & $\begin{array}{c}\text { Investigate real world } \\
\text { data }\end{array}$ \\
\hline iNZight & Design & $\begin{array}{c}\text { Classroom } \\
\text { Use }\end{array}$ & $\begin{array}{c}\text { Design } \\
\text { Classroom } \\
\text { Use }\end{array}$ & $\begin{array}{c}\text { Design } \\
\text { Classroom } \\
\text { Use }\end{array}$ \\
\hline VIT & $\checkmark \checkmark$ & $\checkmark \checkmark$ & $\checkmark$ & $\checkmark$ & $\checkmark \checkmark$ & $\checkmark \checkmark$ \\
\hline GTL & $\checkmark$ & $\checkmark$ & $\checkmark \checkmark$ & $\checkmark \checkmark$ & $\checkmark$ & $\checkmark$ \\
\hline CAST & $\checkmark \checkmark$ & $\checkmark \checkmark$ & & $\checkmark$ & $\checkmark \checkmark$ & $\checkmark$ \\
\hline Commuterview & $\checkmark \checkmark$ & $\checkmark$ & $\checkmark \checkmark$ & $\checkmark \checkmark$ & & $\checkmark$ \\
\hline GeoVista & $\checkmark \checkmark$ & $\checkmark \checkmark$ & & & $\checkmark$ & $\checkmark$ \\
\hline $\begin{array}{l}\text { Dynamic } \\
\text { Pyramid }\end{array}$ & $\checkmark \checkmark$ & $\checkmark \checkmark$ & & & $\checkmark$ & $\checkmark$ \\
\hline Price Kaleidoscope & $\checkmark \checkmark$ & $\checkmark \checkmark$ & & & $\checkmark$ & $\checkmark$ \\
\hline
\end{tabular}

Note: $\checkmark=$ does this to some extent, $\checkmark \checkmark=$ core/ pervasive use.

comparing their design purpose with actual classroom usage. One thing is clear: regardless of the specific function the visualisation tools have been designed for they can be used in statistics classrooms for multiple purposes. Another issue for consideration is whether more of our statistics teaching should be focused on the interpretation of these new visualisation tools as they become more widely used by the media and in the public domain. 
Stern (2012) stated that New Zealand has taken the lead in both its school curriculum and the integration of technological resources for teaching. However, all the resources being used are freely available to the rest of the world and we still have much to learn about the outcomes for statistical education, in terms of the impact of the classroom use of these tools on students' on-going capability in statistics.

\section{REFERENCES}

Bakker, A. (2004). Design research in statistics education: On symbolizing and computer tools. Utrecht, The Netherlands: CD- $\beta$ Press, Center for Science and Mathematics Education.

Budgett, S., Pfannkuch, M., Regan, M., \& Wild, C. J. (2013). Dynamic visualizations and the randomization test. Technology Innovations in Statistics Education, 7(2), 1-21. [Online: http://escholarship.org/uc/item/9dg6h7wb]

Cobb, G. (2007). The introductory statistics course: A Ptolemaic curriculum? Technology Innovations in Statistics Education, 1(1), 1-15.

[Online: http://escholarship.org/uc/item/6hb3k0nz ]

de Róiste, M., Gahagen, M., Morrison, P., Ralphs, M., \& Bucknall, P. (2009). Geovisualisation and policy: exploring the links. Official Statistics Research Project Report. Wellington: Statistics New Zealand.

Engel, A. (1986). Statistics by simulation. Proceedings of the Second International Conference on Teaching Statistics, ICOTS 2.

[Online: http://iase-web.org/documents/papers/icots2/Engel.pdf ]

Finzer, W. (2001). Fathom Dynamic Statistics ${ }^{T M}$ Software, [Computer software]. Key Curriculum Press.

[Online: http://www.keycurriculum.com/products/fathom ]

Forbes, S. D. (2012). Data visualisation: A motivational and teaching tool in official statistics. Technology Innovations in Statistics Education. 6(1), 19 pp.

[Online: http://escholarship.org/uc/uclastat_cts tise]

GeoVISTA Center (2012). Department of Geography, The Pennsylvania State University, University Park, PA.

[Online: http://www.geovista.psu.edu/ ]

Harraway, J. (2012). Learning Statistics Using Motivational Videos, Real Data and Free Software. Technology Innovations in Statistics Education, 6(1), 21 pp.

[Online: http://escholarship.org/uc/item/1fn $7 \mathrm{k} 2 \times 3$ ]

Hesterberg, T. (2006). Bootstrapping students' understanding of statistical concepts. In G. Burrill \& P. Elliot (Eds.), Thinking and reasoning with data and chance (pp. 391-416). Reston, VA: National Council of Teachers of Mathematics.

Hidalgo, C. A. (2010). Graphical Statistical Methods for the Representation of the Human Development Index and its Components. United Nations Development Programme, Human Development Research Paper 2010/39. United Nations, New York. [Online: http://hdr.undp.org/sites/default/files/hdrp 2010 39.pdf ]

Ministry of Education (2012). The New Zealand Curriculum Online. Mathematics and statistics curriculum achievement objectives.

[Online: http://nzcurriculum.tki.org.nz/Curriculum-documents/The-New-Zealand-Curriculum/Learningareas/Mathematics-and-statistics/Mathematics-and-statistics-curriculum-achievement-objectives\# ]

OCED (2011). Better Life Initiative: Measuring Well-being and Progress.

[Online: http://www.oecd.org/statistics/betterlifeinitiativemeasuringwell-beingandprogress.htm]

Parsonage, R., Pfannkuch, M., Wild, C.J., \& Aloisio, K. (2012). Bootstrapping confidence intervals. Pre-proceedings of the 12th International Congress on Mathematics Education, Topic Study Group 12, 8-15 July, Seoul, Korea, (pp. 2613- 2622). [USB]. Seoul, Korea: ICME-12, 2012.

[Online: http://icme12.org/]

Pfannkuch, M., Forbes, S., Harraway, J., Budgett, S., \& Wild, C. (2013). Bootstrapping students' understanding of statistical inference. Summary research report for the Teaching and Learning Research Initiative. 
[Online: http://www.tlri.org.nz/sites/default/files/projects/9295 summary\%20report.pdf]

Pfannkuch, M., Regan, M., Wild, C. J., Budgett, S., Forbes, S., Harraway, J., \& Parsonage, R. (2011). Inference and the introductory statistics course. International Journal of Mathematical Education in Science and Technology, 42(7), 903-913.

Pfannkuch, M. \& Wild, C .J. (2012). Laying foundations for statistical inference. Proceedings of the 12th International Congress on Mathematics Education, Regular Lectures 1-9, 8-15 July, Seoul, Korea, (pp. 317-329). Seoul, Korea: ICME-12.

Pfannkuch, M., \& Wild, C. J. (2013). Working together to improve statistics education: A research collaboration case study. Proceedings of the $59^{\text {th }}$ International Statistical Institute World Statistical Congress, 25-30 August 2013, Hong Kong, China. The Hague, The Netherlands: ISI.

[Online: http://2013.isiproceedings.org/]

Pfannkuch, M., Wild, C. J., \& Parsonage, R. (2012). A conceptual pathway to confidence intervals. ZDM - The International Journal on Mathematics Education, 44(7), 899-911.

Pfannkuch, M., Wild, C. J., \& Regan, M. (2014). Students' difficulties in practicing computersupported statistical inference: Some hypothetical generalizations from a study. In Wassong, T., Frischemeier, D., Fischer, P., Hochmuth, R., \& Bender, P. (Eds.), Mit Werkzeugen Mathematik und Stochastik lernen - Using Tools for Learning Mathematics and Statistics (pp. 393-402). Wiesbaden, Germany: Springer Spektrum.

Robinson, D. R., \& Bowman, A. W. (1990). Computer illustrated texts in statistics. Collegiate Microcomputer, 8(1), 9-13.

Rosling, H. (2007). Gapminder [Computer software]. GapMinder Foundation. [Online: http://www.gapminder.org]

Rossman, A., Dietz, E. J., \& Moore, D. (2013). Interview with David Moore. Journal of Statistics Education, 21(2), 1-18.

[Online: http://www.amstat.org/publications/jse/v21n2/rossmanint.pdf]

Sotos, A., Vanhoof, S., Noortgate, W., \& Onghena, P. (2007). Students' misconceptions of statistical inference: A review of the empirical evidence from research on statistics education. Educational Research Review, 2(2), 98-113.

Stern, D. (2012). Developing statistics education in Kenya through technological innovations at all academic levels. Technology in Statistics Education: Virtualities and Realities-Proceedings of the International Association for Statistical Education Round Table. Philippines. $6 \mathrm{pp}$.

[Online: http://escholarship.org/uc/item/5cc0s29n ]

Stern, D. A., Coe R., Stern, R. D. \& McDermott, B. M. (2012). MSC training in research methods support, Technology in Statistics Education: Virtualities and Realities. Proceedings of the International Association for Statistical Education Round Table. Cebu City, Philippines 2012. 8 pp.

[Online: http://iaseweb.org/Conference_Proceedings.php? $\mathrm{p}=$ Technology_in_Statistics_Education_2012]

Stirling, W. D. (1990). Teaching elementary inference with computer-based simulations, Proceedings of the Third International Conference on Teaching Statistics. 7 pp. [Online: http://iase-web.org/documents/papers/icots3/BOOK2/B3-6.pdf ]

Stirling, W. D. (2002). Interactive content in web pages to teach statistics, Proceedings of the Sixth International Conference on Teaching Statistics, ICOTS $6.5 \mathrm{pp}$. [Online: http://iaseweb.org/documents/papers/icots6/7a3_stir.pdf]

Stirling, W. D. (2013). CAST release 5.3 [Computer software]. [Online: http://cast.massey.ac.nz ]

Tufte, E. (2001). The visual display of quantitative information. Cheshire, CT: Graphics Press.

Wood, M. (2005). The role of simulation approaches in statistics. Journal of Statistics Education, 13(3), 1-11.

[Online: http://www.amstat.org/publications/jse/v13n3/wood.html ]

SHARLEEN FORBES

Victoria University of Wellington P.O. Box 600, Wellington, New Zealand 